\title{
Millau « Condatomagus »
}

Abri de Saint-Amans

\section{(2) OpenEdition Journals}

Édition électronique

URL : http://journals.openedition.org/adlfi/10666

ISSN : 2114-0502

\section{Éditeur}

Ministère de la culture

\section{Référence électronique}

« Millau «Condatomagus » », ADLFI. Archéologie de la France - Informations [En ligne], Midi-Pyrénées, mis en ligne le 01 mars 1997, consulté le 01 mai 2019. URL : http://journals.openedition.org/ adlfi/10666

Ce document a été généré automatiquement le 1 mai 2019

(c) Ministère de la Culture et de la Communication, CNRS 


\title{
Millau « Condatomagus »
}

\author{
Abri de Saint-Amans
}

Date de l'opération : 1988 - 1989 (FP)

Inventeur(s) : Costantini Georges ; Boutin Jean-Yves

1 L'abri de Saint-Amans s'ouvre à l'ouest, à $700 \mathrm{~m}$ d'altitude, sur la rive droite de la Dourbie, à l'extrémité d'un long promontoire rocheux. C'est un vaste abri d'environ $200 \mathrm{~m}^{2}$, de forme sensiblement rectangulaire, prolongé à l'est par une courte galerie coudée et barrée par un mur en pierres sèches. Cet abri se trouve à proximité d'un passage naturel, permettant de circuler sans difficulté majeure d'un causse à l'autre, par le ravin de Langouyes sur le causse Noir et celui de Font-Longue, côté Larzac.

2 Peu de temps après sa découverte en1984, il fut la cible de fouilleurs clandestins ce qui motiva la programmation d'un sauvetage urgent. Au cours des quatre campagnes de fouille,une surface de $160 \mathrm{~m}^{2}$ a été explorée, soit près des quatre cinquièmes du gisement. La stratigraphie est lasuivante :

Le matériel est relativement abondant et varié. On retiendra essentiellement la datation protohistorique de la construction du mur et la présence d'une fosse néolithique structurée. Cette datation haute démontre l'ancienneté de tels aménagements, effectués en vue du parcage d'animaux domestiques (ovi-capridés). Le matériel recueilli évoque une fréquentation qui débute avec le Néolithique ancien et se termine vers les débuts du quatrième siècle de notre ère. Le Néolithique ancien se limite à deux pointes triangulaires. Le stade suivant(Néolithique moyen) est représenté par des vestiges céramiques, lithiques et osseux (propres à la phase classique du Chasséen) et par la fosse structurée,exceptionnelle dans la région des Grands Causses.

Le Chalcolithique reste la principale période d'occupation avec de nombreux foyers et un matériel abondant: haches polies, lames en silex, poinçons, ciseaux, gaines de haches, céramique. L'Âge du bronze a fourni quelques pièces remarquables : poignard à rivets (Fig. $n^{\circ} 1$ : Poignard en bronze à deux rivets en place, de l'Âge du bronze ancien (longueur : $95 \mathrm{~mm})$ ), pointe de flèche du type «Le Bourget ", tasse à anse en ruban. Cette période nous révèle l'ancienneté de l'aménagement en bergerie des abris sous roche. Les débuts de notre ère,avec les monnaies, éléments de ceinture, battant de sonnaille en 
os,démontrent la longue tradition pastorale de ces abris, dont l'utilisation, encore attestée dans des actes du $\mathrm{XV}^{\mathrm{e}} \mathrm{s}$., s'est poursuivie presque jusqu'à nos jours. L'abri de Saint-Amans représente probablement une halte saisonnière fréquentée par quelques individus, lors de déplacements vers le plateau, liés à des activités pastorales. Les sites occupés par les derniers chasseurs du Mésolithique, les populations du Néolithique ancien ou les Chasséens dans cette portion de la vallée de la Dourbie sont rares.

Le Chalcolithique est synonyme d'explosion démographique, ce qui entraine la première exploitation intensive du plateau. L'élevage des ovi-capridés s'y développe et l'agriculture contribue à l'expansion du groupe. On note la présence de grandes lames en silex au lustré caractéristique. L'augmentation du volume des récipients (grands vases-silos) dénote une productivité et un stockage plus important. C'est encore à partir de cette époque que vont être utilisés les avens-citernes pour l'approvisionnement en eau. Les sépultures collectives sont la règle (dolmens et cavités sépulcrales).

\section{ANNEXES}

Fig. $\mathrm{n}^{\circ} 1$ : Poignard en bronze à deux rivets en place, de l'Âge du bronze ancien (longueur : $95 \mathrm{~mm}$ )

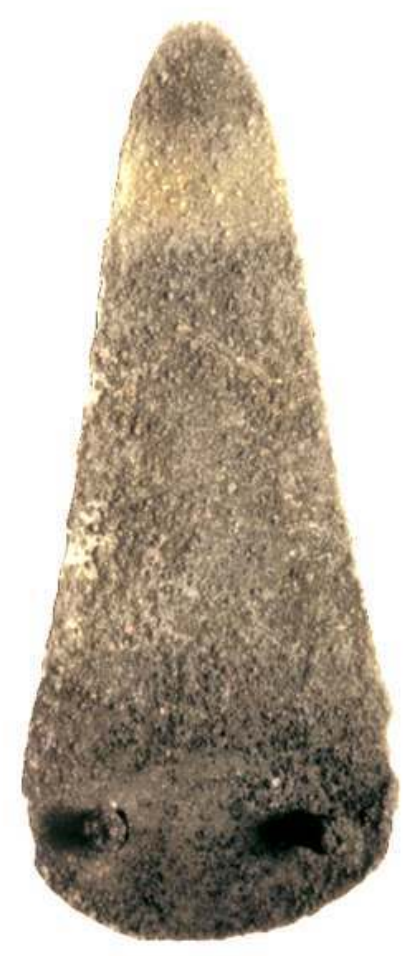

Auteur(s) : Costantini, Georges. Crédits : Gl, 1997 ; CNRS Éditions 1998 (1989) 
INDEX

operation Fouille programmée (FP)

peuple Chasséen

Index chronologique : âge du Bronze, Chalcolithique, Néolithique final

Index géographique : Midi-Pyrénées, Aveyron (12), Millau 